\title{
ВАЖНЫЕ АСПЕКТЫ БИЗНЕС-ПЛАНИРОВАНИЯ ИННОВАЦИОННЫХ ПРОЕКТОВ
}

\section{(c) 2021 Шкарина Татьяна Юрьевна}

кандидат экономических наук, доцент, профессор, департамент инноваций Дальневосточный федеральный университет, Россия, Владивосток

\section{(c) 2021 Сидорова Наталья Георгиевна}

кандидат экономических наук, доцент, профессор, департамент инноваций Дальневосточный федеральный университет, Россия, Владивосток

E-mail:n0656@yandex.ru

\section{(c) 2021 Быватов Артем Павлович}

магистрант, Политехнический институт, инноватика

Дальневосточный федеральный университет, Россия, Владивосток экономист МКУ «Центр развития предпринимательства», Россия, Владивосток

E-mail: artembyvatov@yandex.ru

На ранних стадиях инновационного проекта важной составляющей с учетом повышенной степени неопределённости является бизнес-планирование. В рамках бизнес-планирования инициатору проекта необходимо сформировать целостную картину будущего предприятия с минимальными затратами и подтвердить экономическую целесообразность предлагаемого решения. В данной статье рассмотрены девять ключевых составляющих бизнес-модели инновационного проекта (ключевые партнеры, ключевые виды деятельности, ценностные предложения, ресурсы, каналы сбыта, взаимоотношения с клиентами, потребительские сегменты, структура издержек, потоки поступления доходов). При описании каждой составляющей бизнес-модели продемонстрирован подход к учету и управлению рисками проекта. В рамках статьи раскрыт современный инструмент «Бизнеснавигатор МСП», представляющий собой информационный ресурс и разработанный в целях обеспечения организации оказания маркетинговой и информационной поддержки субъектам малого и среднего предпринимательства, в соответствии с частью 2 статьи 25.1 Федерального закона от 24.07.2007 № 209-Ф3 «О развитии малого и среднего предпринимательства в Российской Федерации». Представленная в статье информация начинающим инноваторам даст ценные знания и инсайты, которые в дальнейшей практике позволят эффективно реализовывать проекты в условиях неопределенности.

Ключевые слова: бизнес-планирование, инновационный проект, бизнес-модель, риск, бизнес-план, план управления рисками, малый и средний бизнес, реестр рисков

Инновационная деятельность предполагает принятие решений в условиях неопределенности, подразумевающей наличие ряда рисков. Исходя из данного факта требуется грамотно и выверенно планировать свою деятельность с минимальными издержками перед началом реализации инновационного проекта с целью достижения целевых показателей проекта.

Здесь эффективным инструментом планирования и экономического обоснования целесообразности реализации проекта является бизнес-план. Бизнес-план в современной экономике зачастую используется как инструмент, презентующий инновационный проект перед венчурным инвестором, фондом, банком и бизнес-ангелом с целью привлечения средств в будущее предприятие. Эффективность данного инструмента заключается в демонстрации целостной картины будущего проекта с учетом всех ключевых аспектов бизнеса, подкрепленных финансовой моделью. Для понимания того, что именно нужно описать в каждом разделе бизнес-проекта необходимо остановиться на бизнес-модели. Концептуальное описание будущего проекта должно быть отражено в бизнесмодели [1]. Шаблон бизнес-модели представлен на рисунке 1.

Блок потребительских сегментов описывает 


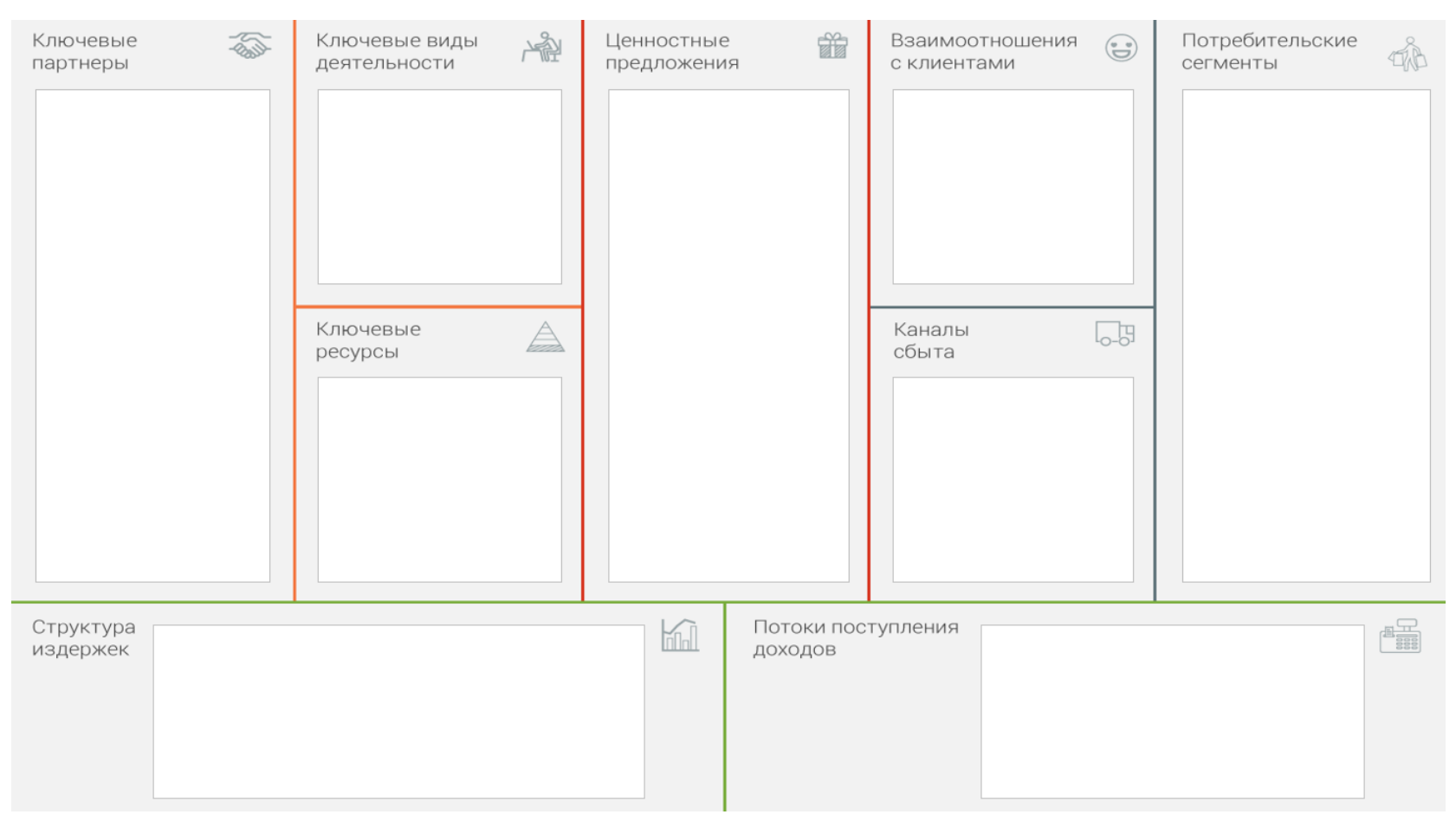

Рисунок 1. Шаблон бизнес-модели инновационного проекта [1]

какие группы людей и предприятий будущий проект планирует обслуживать. В данном блоке необходимо ранжировать целевую аудиторию по группам потребностей, особенностям поведения, ценностям и другим значимым признакам.

Блок ценностных предложений описывает товары и услуги, которые представляют ценность для потребительских сегментов. Ценностные предложения представляет собой причину, по которой клиенты отдают предпочтение вашему проекту.

Каналы сбыта. Данный блок описывает, каким образом компания или проект взаимодействуют с потребительскими сегментами и доносят до них свои ценностные предложения.

Взаимоотношения с клиентами. Блок описывает типы отношений, с отдельными потребительскими сегментами. Компания должна четко сформулировать, какой тип взаимоотношений наиболее эффективен с каждым потребительским сегментом и в соответствии с этим выстроить коммуникацию.

Потоки поступления дохода. Данный раздел включает прибыль, которую компания планирует получить в процессе реализации товаров и услуг. Бизнес-модель может совмещать доход от регулярных платежей и разовых сделок, получаемых от клиентов за ценностные предложения или пост продажное обслуживание.
Ключевые ресурсы. В данном разделе описываются важнейшие активы, необходимые для эффективного функционирования бизнесмодели. Эти ресурсы позволяют компании генерировать ценностные предложения, выходить на рынок, поддерживать связи с потребителями своей продукции и получать прибыль.

Ключевые партнеры. Блок описывает поставщиков и партнеров, благодаря которым бизнес-модель будет генерировать прибыль.

Структура издержек. Блок описывает наиболее значимые для проекта расходы, необходимые для работы в рамках конкретной бизнесмодели. Генерация и реализация ценностных предложений, поддержание взаимоотношений с клиентами, получение прибыли - все эти процессы связаны с какими-либо издержками. Важно при формировании бизнес-модели пользоваться инструментами, требующими минимальных затрат.

Проведя трехлетнее исследование в сфере малого и среднего предпринимательства (далее МСП) Владивостокского городского округа, нами был сформулирован инсайт о том, что предпринимательское сообщество в большинстве не имеет представления о существующем бесплатном информационном ресурсе «Бизнеснавигатор МСП»», разработанным в целях обеспечения организации оказания маркетинговой 
и информационной поддержки субъектам МСП, в соответствии с частью 2 статьи 25.1 Федерального закона от 24.07.2007 № 209-Ф3 «О развитии малого и среднего предпринимательства в Российской Федерации». «Бизнес-навигатор МСП» предоставляет уникальную возможность изучить конкурентную среду и рассчитать бизнес-план с учетом среднегодовой инфляции. Пример выбора будущего места реализации проекта представлен на рисунке 2.

Стоит отметить, что система дает возможность сделать усредненную характеристику рыночной ниши с указанием населения вблизи локации проекта (с ранжированием покупателей на группы по уровню дохода) и среднего чека. Бизнес-план формируется на основе существующей практики ведения бизнеса в соответствии с действующим законодательством РФ и существующих рыночных индикаторов. Базой для расчета системой примерных бизнес-планов являются усредненные данные о более чем 20000 реальных успешных предприятий малого бизнеса, проверенных экспертами отраслевых профессиональных объединений, описывающих основные показатели создания (инвестиционная программа) и ведения (формат обслуживания, операционные затраты) бизнеса. Формат и состав примерного бизнес-плана согласован обще- ственными деловыми объединениями предпринимателей: «Деловая Россия, «ОПОРА России», Российский союз промышленников и предпринимателей, Торгово-промышленная палата Российской Федерации; крупнейшими банками, а также Агентством стратегических инициатив [2]. Важно помнить, что ввиду высоких рисков, сопровождающих реализацию инновационных проектов в сравнении с классическими инвестиционными проектами, необходимо сформировать план управлении рисками проекта с целью минимизации возможных негативных последствий. План управления проектами должен быть утвержденными и подписанным документом, включающим в себя роли и полномочия участников, этапы процесса управления рисками; приложения (реестр рисков проекта). План управления рисками инновационных проектов, представлен на рисунке 3,4,5,6.

Представленный план управления рисками позволит контролировать проект и предвосхищать, устранять или минимизировать негативные последствия. Важным фактом является то, что представленный план позволит сформировать реестр рисков с назначенными ответственными лицами и как следствие позволит эффективно нивелировать возможные негативные последствия в процессе реализации проекта.

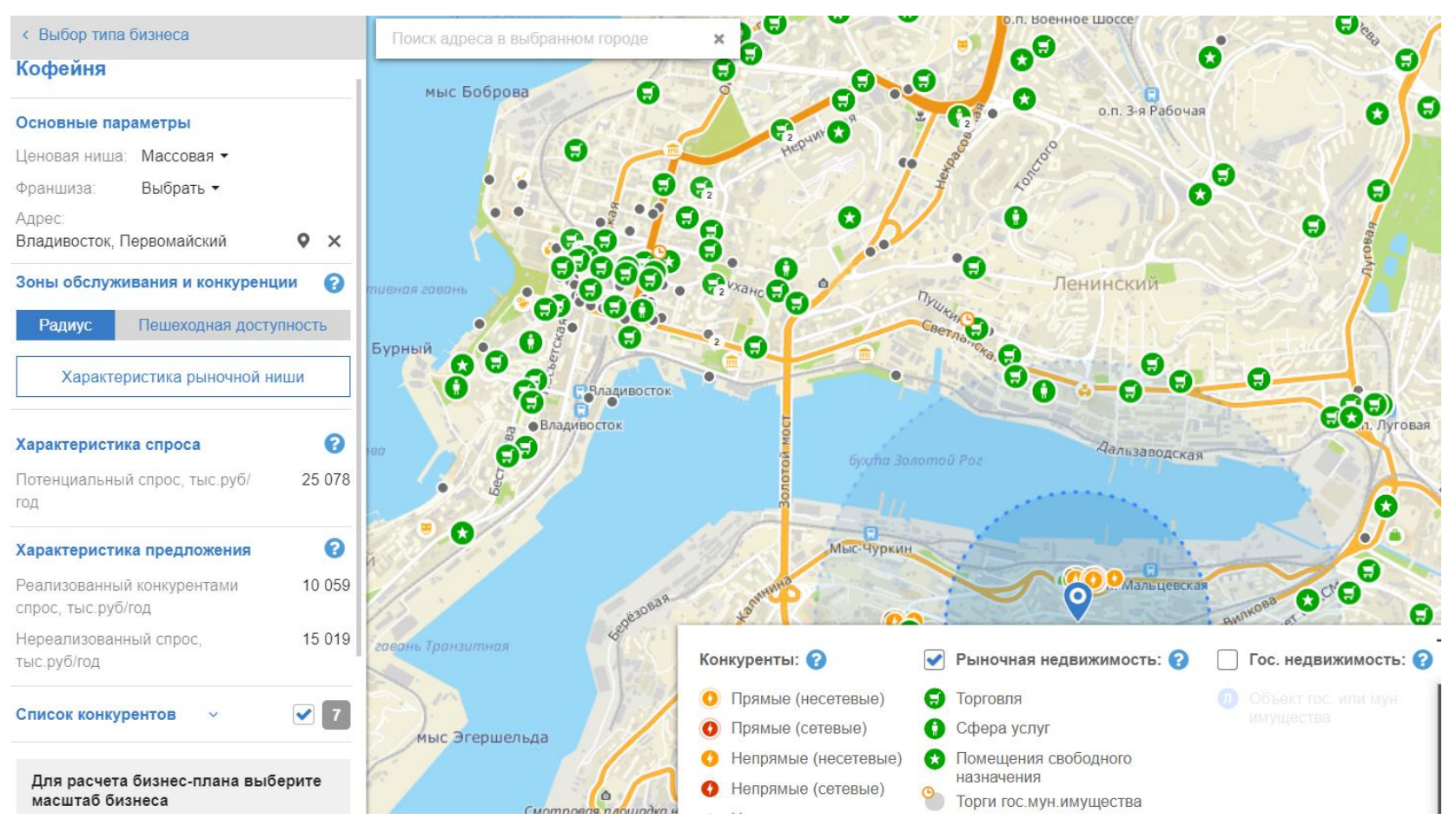

Рисунок 2. Выбор местоположения проекта [2] 
Таблица 1. Роли и полномочия участников проекта (пример заполнения)

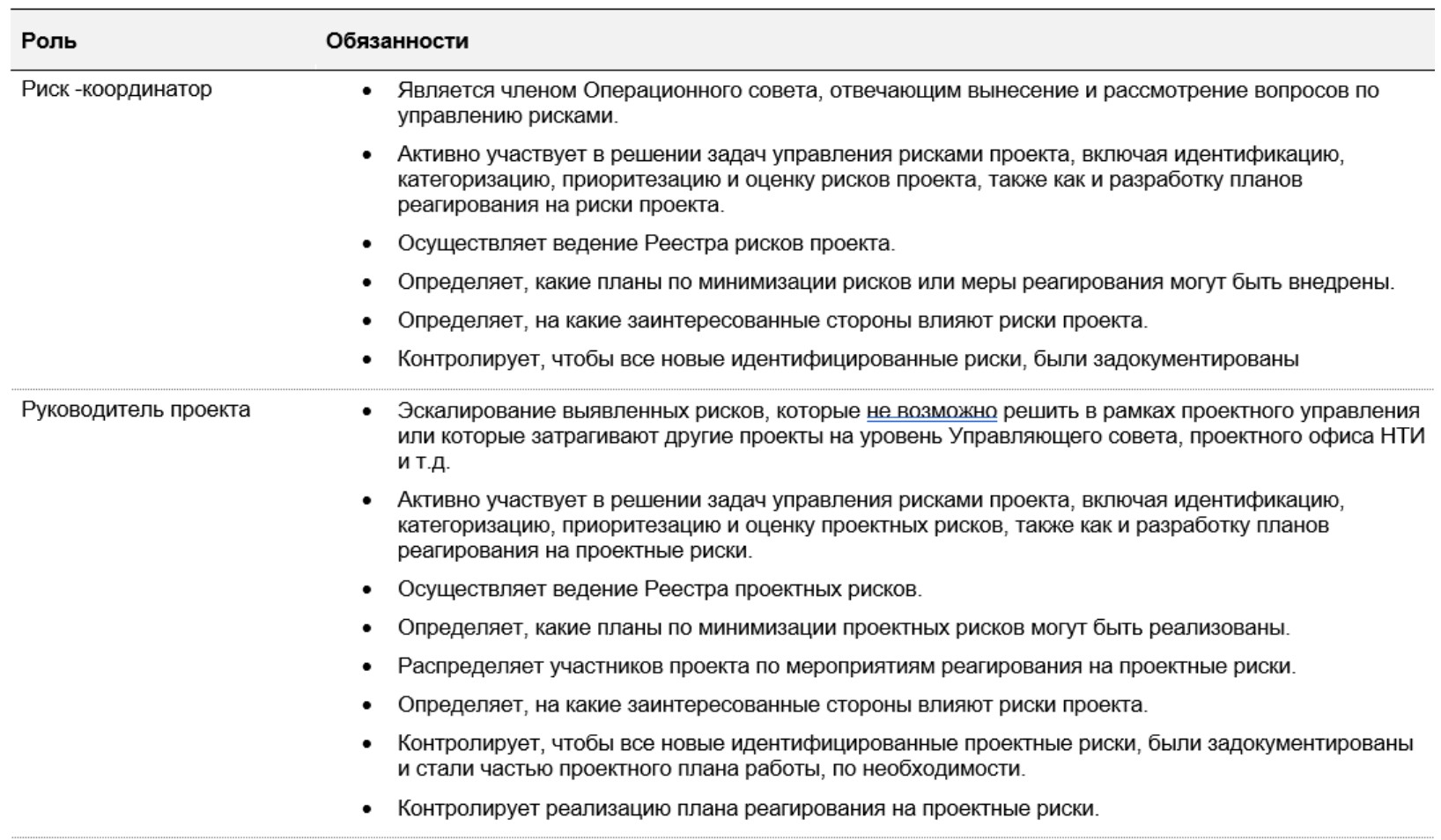

Рисунок 3. Роли и полномочия участников проекта [3]

\section{ЭТАПЫ ПРОЦЕССА УПРАВЛЕНИЯ РИСКАМИ ПРОЕКТА}

\section{ОЦЕНКА РИСКОВ}

Расстановка приоритетов по работе с рисками в процессе реализации проекта будет осуществляться на основании классификации величины рисков. Оценка важности каждого риска и, следовательно, его приоритета осуществляется с помощью матрицы величинь рисков. Оценка вероятности и степени влияния производится в соответствии с подходом, описанном в Методических указаниях по описанию проектов НТИ.

\section{РЕАГИРОВАНИЕ НА РИСК}

При заполнении реестра рисков определите для каждого риска одну из предоставленных ниже стратегий:

Таблица 2. Стратегии реагирования на риски

\begin{tabular}{lll}
\hline № & Вид стратегии & Действие \\
\hline 1 & Принятие & $\begin{array}{l}\text { Активное реагирование не предпринимается. При планировании создается резерв ресурсов, размер } \\
\text { которого зависит от оценки риска. }\end{array}$ \\
\hdashline 2 & Уклонение & $\begin{array}{l}\text { Пересмотр задач или плана выполнения проекта вплоть до отказа от части мероприятий с целью } \\
\text { недопущения возможной реализации риска. }\end{array}$ \\
\hdashline 3 & Снижение & $\begin{array}{l}\text { Планирование и осуществление мероприятий, направленных на сокращение влияния и/или вероятности } \\
\text { наступления рискового события. }\end{array}$ \\
\hline 4 & Передача & $\begin{array}{l}\text { Институциональное перенесение ответственности и последствий в случае наступления рискового события } \\
\text { на внешних контрагентов. }\end{array}$ \\
\hline
\end{tabular}

Рисунок 4. Этапы процесса управления рисками проекта [3] 


\begin{tabular}{|c|c|c|c|c|c|}
\hline № & Действия & Периодичность & Кем будет проводиться & Формат & Комментарий \\
\hline \multicolumn{6}{|c|}{$\begin{array}{c}\text { Идентификация и оценка рисков } \\
\text { (выберите необходимые инструменты из пунктов 1-10. Инструменты, которые вы не будете использовать, удалите) }\end{array}$} \\
\hline 1. & $\begin{array}{l}\text { Оценка рисков на } \\
\text { основе контрольных } \\
\text { листов }\end{array}$ & $\begin{array}{l}\text { Укажите } \\
\text { периодичность } \\
\text { действия } \\
\text { Раз в неделю }\end{array}$ & $\begin{array}{l}\text { Укажите, кто будет } \\
\text { проводить действие } \\
\text { Например: } \\
\text { - Оперативный совет } \\
\text { - Руководитель проекта } \\
\text { - } \\
\text { - Риск координатор } \\
\text { Руководители } \\
\quad \text { функциональных групп }\end{array}$ & $\begin{array}{l}\text { Например: } \\
\text { Совещание. } 1 \text { час } \\
\text { Совещание. } 2 \text { часа } \\
\text { ВКС. } 1 \text { час } \\
\text { Оперативный совет в } \\
\text { соответствии с } \\
\text { повесткой }\end{array}$ & $\begin{array}{l}\text { Простая форма идентификации риска. } \\
\text { Метод позволяет } \\
\text { представить пользователю перечень } \\
\text { источников неопределенности, } \\
\text { которые необходимо рассмотреть. } \\
\text { Пользователи } \\
\text { используют ранее разработанный } \\
\text { перечень, кодексы (своды правил) и } \\
\text { стандарты }\end{array}$ \\
\hline 2. & $\begin{array}{l}\text { Опрос экспертов, } \\
\text { интервью }\end{array}$ & Два раза в месяц & & & $\begin{array}{l}\text { Способ получения набора идей и оценок, } \\
\text { ранжируемых } \\
\text { командой. }\end{array}$ \\
\hline 3. & Мозговой штурм & Раз в неделю & & & $\begin{array}{l}\text { Мозговой итурм можно } \\
\text { стимулировать путем применения } \\
\text { методов интервью «один на один» или } \\
\text { «один с группой» }\end{array}$ \\
\hline 4. & $\begin{array}{l}\text { Анализ воздействия } \\
\text { на бизнес }\end{array}$ & Раз в неделю & & & $\begin{array}{l}\text { Метод позволяет провести анализ } \\
\text { риска нарушения (разрушения) } \\
\text { ключевых видов деятельности } \\
\text { ореанизации и идентифицировать }\end{array}$ \\
\hline
\end{tabular}

Рисунок 5. Идентификация и оценка рисков [3]

\begin{tabular}{|c|c|c|c|c|c|c|c|c|c|}
\hline Дата регистрации риска & $\begin{array}{c}\text { Развернутое } \\
\text { описание риска }\end{array}$ & $\begin{array}{l}\text { Стратегия } \\
\text { реагирования }\end{array}$ & $\begin{array}{l}\text { Категория } \\
\text { риска }\end{array}$ & $\begin{array}{l}\text { Вероятность } \\
\text { наступления }\end{array}$ & $\begin{array}{l}\text { Степень } \\
\text { влияния }\end{array}$ & Величина риска & $\begin{array}{l}\text { Итоговая } \\
\text { ВЕличИНА } \\
\text { РИСКА }\end{array}$ & Триггер риска & Владелец риска \\
\hline $\begin{array}{l}\text { Дата занесения риска в реестр } \\
\text { Например: 20.09.2016 }\end{array}$ & \begin{tabular}{|l|} 
Подробное \\
описание риска \\
объемом свыше 50 \\
символов (если \\
требуется). \\
Например: \\
Невозможность \\
предоставления \\
рабочего места \\
для всей \\
проектной \\
команды в офисе \\
Заказчика, ОАО \\
Ромашка
\end{tabular} & & кадровый & Низкая & Очень высокая & СРЕДНИЙ & 2 & \begin{tabular}{|l|} 
Показатель раннего \\
оповещения о реализации \\
или скорой реализации \\
риска, который должен \\
запускать меры по \\
реагированию на риск. \\
заполняется текстовым \\
описанием. \\
Наприер:Непредоставлени \\
е рабочих мест для \\
команды в течение трех \\
недель с момента старта \\
проекта
\end{tabular} & $\begin{array}{l}\text { Ответственное лицо за } \\
\text { реализацию } \\
\text { осуществления } \\
\text { мероприятий, } \\
\text { направленных на } \\
\text { сокращение влияния } \\
\text { и/или вероятности } \\
\text { наступления рискового } \\
\text { события (снижение } \\
\text { величины риска), а } \\
\text { также мероприятий } \\
\text { реагирования на риск. } \\
\text { Например: Куратор } \\
\text { проекта }\end{array}$ \\
\hline
\end{tabular}

Рисунок 6. Реестр рисков проекта [3]

Специфика реализации инновационных проектов заключается в заведомо высоком уровне риска в сравнении с классическими инвестиционными проектами, ввиду создания принципиального нового продукта или услуги. Ввиду данного факта идентификация, управление и минимизация рисков являются одним из ключевых процессов при реализации проекта.

Представленный шаблон бизнес-модели и подход к работе с рисками позволит начинающему предпринимателю увидеть целостную картину проекта и учесть возможные неблагоприятные факторы, которые могут повлиять на конечную цель проекта. Используя указанную в статье информацию при написании бизнесплана, инициатор проекта сможет обосновать экономическую выгоду от реализации проекта и привлечь необходимые инвестиции в будущее предприятие с учетом специфики рынка реализации проекта. В ходе исследования получены следующие результаты:

1. Продемонстрированы девять ключевых составляющих бизнес-модели проекта и раскрыта их суть;

2. Предложен уникальный инструмент маркетинговой и информационной поддержки бизнеса «Бизнес-навигатор МСП»;

3. Сформирован подход к учету и управлению рисками проекта;

4. Предложен эффективный инструмент по управлению рисками проекта.

Приведенная в статье информация позволит инициаторам инновационных проектов учесть многие факторы при планировании проекта и как следствие повысит шанс на успешную реализацию. 


\section{Библиографический список}

1. И. Пинье, А. Остервальдер. Построение бизнес-моделей. Настольная книга стратега и новатора. М.: Альпина Паблишер, 2019. С. 19-44 С.

2. Расчет бизнес-плана [Электронный ресурс] / Информационный ресурс Бизнес-навигатор MCП. URL: https:/ navigator.smbn.ru/st/13/prom (дата обращения 12.05.2021).

3. План управления рисками проекта НТИ [Электронный ресурс] / NTI2035. URL: https://nti2035.ru/documents/ templates/ (дата обращения 13.05.2021). 